\title{
Detection and Characterization of Methicillin Resistant Staphylococcus aureus from Toilet and Classroom Door Handles in Selected Secondary Schools in Nairobi County
}

\author{
Caroline Mbogori $^{{ }^{*}}$, Anne Muigai ${ }^{1}$, Samuel Kariuki ${ }^{2}$ \\ ${ }^{1}$ Jomo Kenyatta University of Agriculture and Technology, Itromid KEMRI, Nairobi, Kenya \\ ${ }^{2}$ Centres for Microbiology Research, KEMRI, Nairobi, Kenya \\ Email: "carombogori@yahoo.com
}

Received October 23, 2013; revised November 22, 2013; accepted November 29, 2013

Copyright (C) 2013 Caroline Mbogori et al. This is an open access article distributed under the Creative Commons Attribution License, which permits unrestricted use, distribution, and reproduction in any medium, provided the original work is properly cited. In accordance of the Creative Commons Attribution License all Copyrights (C) 2013 are reserved for SCIRP and the owner of the intellectual property Caroline Mbogori et al. All Copyright (C) 2013 are guarded by law and by SCIRP as a guardian.

\begin{abstract}
Background: Staphylococcus aureus is found on all surfaces especially in public areas like hospitals and schools and on frequently touched areas like toilet and classroom door handles. Methicillin resistant Staphylococcus aureus (MRSA) is a strain of Staphylococcus aureus which is resistant to methicillin. There are two types of MRSA: Community acquired methicillin resistant Staphylococcus aureus (CA-MRSA) and hospital acquired methicillin resistant Staphylococcus aureus (HA-MRSA). MRSA in the community presents a significant reservoir that could enter into healthcare facilities and spread among patients and also a risk for immune compromised persons in the community. Methodology: The study aimed at determining the prevalence of MRSA isolated from toilet and classroom door handles as a potential source of infection to the students and the workers in selected schools in Nairobi, Kenya. The study also compared the prevalence of MRSA between boarding and non-boarding girls, boys and mixed (both girls and boys in the same school) secondary schools. Twelve secondary schools in Nairobi County were randomly selected and 306 samples from both the toilet and classroom door handles were collected using sterile swabs and transported to the laboratory. Isolation of Staphylococcus aureus was done by the use of selective media Mannitol salt agar, antibiotic susceptibility of isolates was done by disk diffusion method, and molecular detection of mecA and PVL genes were done by polymerase chain reaction (PCR). Results: The prevalence of S. aureus was $20 \%$ and $15 \%$ were MRSA positive by both Antimicrobial Susceptibility Test and PCR detection. 20\% showed the presence of PVL genes, $8 \%$ showed the presence of both genes and $56 \%$ of isolates with mecA gene had PVL genes. Conclusion: The presence of MRSA in this study emphasizes the need to formulate hygiene measures to prevent possible spread of MRSA and other transmissible pathogens to students and workers in the schools.
\end{abstract}

Keywords: Methicillin Resistant Staphylococcus aureus; Secondary Schools; Antibiotic Patterns

\section{Introduction}

Staphylococcus aureus is a gram positive coccus, catalase positive, mainly coagulase positive, non-motile bacterium [1]. The bacterium is found in a wide range of habitats including environmental surfaces, in nasal nares of domesticated animals like dogs, cats and horses and on human body surfaces [2] as a part of normal microflora. However, S. aureus can also cause a variety of infections in animals, for instance, mastitis in dairy cows, septicae-

${ }^{*}$ Corresponding author. mia and arthritis in poultry and genital tracts infections of animals. The large polysaccharide capsule of the organism protects it from recognition by the immune system of the cow [3]. S. aureus in humans is found on the mucus membranes, for example, the nasal passages and the human skin of around a third of the population and, it is well adaptable to antibiotic pressure, therefore it is able to colonize healthy individuals which can be a source of infections and spread among people [4]. People with suppressed immunity due to the use of suppressive drugs and other diseases that cause immune diseases are at higher risk of acquiring S. aureus infections. S. aureus is able to 
combine a number of bacterial immuno-evasive strategies to invade humans; these strategies include production of virulence factors like carotenoid pigment Staphyloxanthine responsible for the golden colour of S. aureus colonies on a culture media. This factor helps the bacteria to evade reactive oxygen species which are used by the host to kill the pathogens [5]. S. aureus can cause three types of infections: Superficial lesions like pimples, impetigo, boils, cellulitis, scalded skin syndrome (SSS) and abscesses; toxicosis like food poisoning, toxic shock syndrome (TSS) and systemic infections like endocarditis, brain abscesses and meningitis, osteomyelitis, bacteremia and sepsis [6]. S. aureus has been known to possess antibiotic resistance genes; these genes includes mecA gene which leads to methicillin resistance [7]. S. aureus was one of the first bacteria in which penicillin resistance was found in 1947 four years after the drug started to be produced. S. aureus is also resistant to a number of antibiotics which include beta lactam antibiotics like penicillin, amoxylin and oxacillin. Treatment of S. aureus infections has been difficult due to its ability to resist the commonly used drugs in the hospitals; methicillin was the drug of choice but has been replaced by oxacillin due to significant kidney toxicity [8]. In the USA, half of the S. aureus infections are resistant to penicillin, methicillin, tetracycline and erythromycin leaving vancomycin as the only drug of choice. In recent studies, strains which are resistant to vancomycin have been identified and are called vancomycin intermediate resistance S. aureus (VISA) and vancomycin resistant $S$. aureus (VRSA) [8]. Prevention of the S. aureus infection is diverse and may include hand-washing, use of disposable aprons and gloves in the hospitals to reduce skin contacts. Disinfectants like ethanol, quaternary compounds and sodium hypochlorite are used to disinfect surfaces [9]. The study aims at determining if there is presence of MRSA in secondary schools in Nairobi County and the prevalence of MRSA in these schools. Presence of MRSA in schools posses a significant source of infections to the community and possible entry of MRSA in the health facilities. The immune-compromised persons, who are also at risk of getting infected if in contact with the pathogen students in the day schools, are more likely to transfer the MRSA to their homes when they go home. Home is the meeting place for all the other family members who might spread the bacteria to other areas in the community.

\section{Methodology}

Study site: The study was conducted in selected secondary schools in Nairobi, Kenya

Study population: The study population included selected secondary schools in Nairobi, Kenya and whose the head teachers of the schools had given consent to participate in the study.

Study design: A cross-sectional study design was used. The schools were selected randomly

\subsection{Study Information and Consent from the Headteachers}

The selection of the schools was done from a list of all the secondary schools in Nairobi, Kenya. The head teachers of the selected schools were given the information about the study and were asked for their consent to participate in the study. The head teachers were asked to sign the consent form.

\subsection{Sample Collection}

A total of 306 swabs were collected from door handles of the both the class rooms doors and the toilets in randomly selected secondary schools in Nairobi Kenya.

The samples were collected using sterile swabs moistened using buffered peptone water by swabbing the toilet and the classroom door handles. The samples were properly labeled using reference numbers so that the identity of the school was anonymous and then transported to the Laboratory using buffered peptone water transport media. Student's toilets, school workers toilets, class rooms and visitors' toilets in each school were swabbed.

\subsection{Laboratory Procedures}

\subsubsection{Culture of the Samples}

In the laboratory the sample in the tube were thoroughly mixed to suspend the microorganisms into the buffered peptone water solution. The suspension was inoculated into Mannitol salt aga media. The samples were then incubated at $35^{\circ} \mathrm{C}$ for 22 hours. Mannitol Salt Agar is used for the selective isolation and enumeration of Staphylococcus aureus from clinical and nonclinical materials. Only Staphylococcus aureus grow on agar media containing $7.5 \%$ sodium chloride. Addition of $7.5 \%$ sodium chloride to phenol red mannitol agar results in an improved medium for the isolation of plasma coagulating staphylococci. The $7.5 \%$ concentration of sodium chloride results in the partial or complete inhibition of bacterial organisms other than staphylococci. Mannitol fermentation, as indicated by a change in the phenol red indicator, aids in the differentiation of staphylococcal species.

The identity of the isolates was confirmed by standard laboratory methods which included colony morphology, gram staining, catalase test and coagulase test.

\subsubsection{Preservation of Staphylococcus aureus Isolates}

Two or three colonies of the isolates were diluted to 2 Mac Farland standard in $2 \mathrm{mls}$ of sterile tryptic soy broth. 
One $\mathrm{ml}$ of the organism was put into a cryo vial containing one $\mathrm{ml}$ of sterile tryptic soy broth with $15 \%$ glycerine, then sealed with a cock and stored at $-80^{\circ} \mathrm{C}$.

\subsubsection{Antimicrobial Susceptibility Testing}

Antimicrobial susceptibility testing was done by use of Kirby Bauer disk diffusion method under Clinical Laboratory Standards Institute (CLSI) 2011 guide lines. Five colonies of the organism were emulsified in $5 \mathrm{mls}$ of sterile normal saline and mixed well; the turbidity was compared to 0.5 Mac Farland standard.

A sterile cotton swab was used to inoculate the sample into Mueller-Hinton agar plates and allowed to dry. The following antibiotics were used; oxacillin (30 $\mu \mathrm{g}$ cefoxitin), 20/10 $\mu \mathrm{g}$ amoxicillin/clavulanic acid,10 $\mu \mathrm{g}$ gentamycin, $30 \mu \mathrm{g}$ ceftazidime, $30 \mu \mathrm{g}$ vancomycin, $5 \mu \mathrm{g}$ Levofloxacin, $10 \mu \mathrm{g}$ ampicillin, $30 \mu \mathrm{g}$ tetracycline, 1.25/ $23.75 \mu \mathrm{g}$ trimethoprim-sulfamethoxazole and $15 \mu \mathrm{g}$ erythromycin. Zone of inhibitions were determined by measuring the size of clear zones and compared to the CLSI. The reporting was done by indicating Resistant, Intermediate or Sensitive.

S. aureus ATCC 25923 was used as positive control organism

\subsection{Detection of MRSA by Disc Diffussion}

Methicillin resistance was determined by testing resistance to $30 \mu \mathrm{g}$ Cefoxitin. If the inhibition zone for cefoxitin was $\leq 21 \mathrm{~mm}$, the culture was considered as positive for MRSA. Cefoxitin was used as a surrogate for oxacillin resistance. The result was reported as oxacillin susceptible or resistant based on the cefoxitin result. The results indicated the presence of MRSA (CLSI Guidelines).

\subsection{Detection of mecA and PVL Genes}

The DNA isolation was done using Spin protocol method using the QIAGEN kit. The kit is made by QIAGEN Inc, Hilden-Germany. The amplification was done using GenoTypeMRSA assay kit. Thermocycler ABI 2720 was used for amplification. The identification of the mecA gene and PVL gene was done through reverse hybridization. The kit identifies both the mecA gene and the PVL gene. The presence of mecA gene was considered as MRSA positive. PVL gene detection in this study was based on the rational that it is mainly found in CAMRSA.

Statistical analysis: Data entry and analysis were performed using Ms excel.

Ethical approval for the study: Ethical clearance for the study was obtained from KEMRI Scientific Steering Committee and Ethical Review Committee

\section{Results}

\subsection{Prevalence of Staphylococcus aureus}

A total of 306 samples collected from selected secondary schools were processed and 61 samples were positive for S. aureus (20\%) (Table 1).

\subsection{Antibiotic susceptibility of Staphylococcus aureus Isolates}

Antibiotic susceptibility testing was performed on all the 61 isolates. Shows the proportion of isolates, classified as susceptible, intermediate or resistant to the antibiotics that were tested and these results are presented in Figure 1.

There were 14 isolates (15\%) which were resistant to Cefoxitin and 47 isolates (85\%) were sensitive. The highest level of resistance was to trimethoprim/sulfamethoxazole, with 37 isolates (61\%) exhibiting complete resistance. Only $14 \%$ of the isolates were sensitive to trimethoprim/sulfamethoxazole 54 isolates (88\%) were susceptible to amox/clav and $10 \%$ were resistant. All the isolates were sensitive to Tetracycline, Erythromycin, Levofloxacin, Gentamycin, Ampicillin, Vancomycin and Clindamycin.

\subsection{Staphylococcus aureus Distribution}

S. aureus was more prevalent in Girls' schools than in boys' schools. S. aureus was also found in mixed schools and non in boys'schools (Table 2).

\subsection{Presence of MecA Gene and PVL Gene}

Out of 61 isolates of S. aureus 9 (15\%) isolates contained

Table 1. Results for Staphylococcus aureus isolation.

\begin{tabular}{|c|c|c|}
\hline \multicolumn{2}{|c|}{ Staphylococcus aureus isolation } & \multirow{2}{*}{ Total } \\
\hline Positive & Negative & \\
\hline 61 & 245 & 306 \\
\hline
\end{tabular}

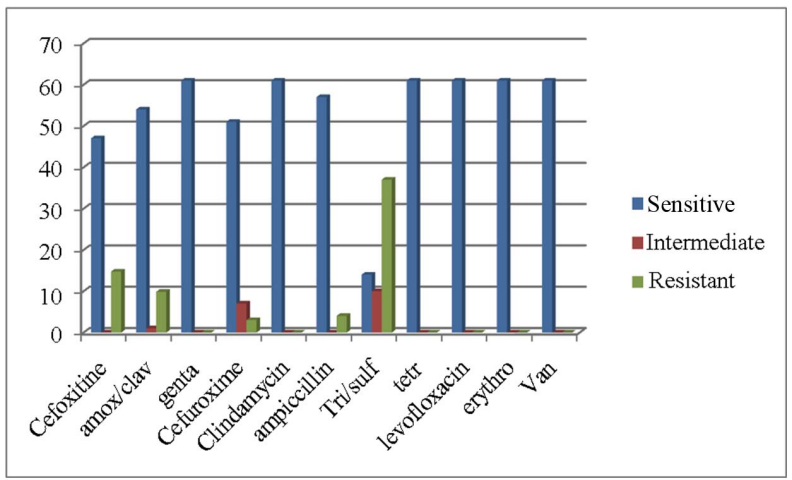

Figure 1. Anti-microbial susceptibility of Staphylococcus aureus isolates. 
Mec $A$ gene and 12 (20\%) had the PVL genes. Five (8\%) isolates had both Mec $A$ and PVL genes. This is way below the percentage from a study done in Iraq holy shrine where MRSA with PVL gene was 27\% [13]. Table 3 shows the percentage of S.aureus isolates carrying both Mec A and PVL gene detected by PCR analysis.

\section{Discussion}

\subsection{Prevalence of $S$. aureus in Schools}

A prevalence of $20 \%$ of $S$. aureus was observed in this study. Out of the 61 S. aureus isolated 14 (15\%) were MRSA using the disk susceptibility tests. A study carried out in Nairobi showed a prevalence of $41 \%$ of $S$. aureus isolated from community acquired infections [10], these findings were much higher than the ones found in this study. However, in almost a similar study done in Lagos, Nigeria $20 \%$ of all isolates obtained on the telephone booths receivers were $S$. aureus. Lack of published data documenting patterns of $S$. aureus in secondary schools in both Kenya and in Africa precludes my ability to determine wether there has been an increase of the bacteria in the secondary schools environment.

\subsection{Antimicrobial Susceptibility}

Trimethoprim/sulfamethoxazole: A high resistant rate (61\%) was observed in the isolates. In almost a similar study in Lagos, Nigeria, isolates from telephone handles were $100 \%$ resistant to Trimethoprim/sulfamethoxazole: [11].

Erythromycin: Resistance of 0\% was seen among the isolates in this study. This was a great difference compared to $100 \%$ resistance of the same drug done in a study

Table 2. Distribution of the identified $S$ aureus in different types schools.

\begin{tabular}{ccc}
\hline Type of school & Frequency & Percentage Distribution \\
\hline Boarding Girls schools & 2 & 33 \\
Boarding Boys schools & 0 & 0 \\
Mixed Boarding schools & 1 & 17 \\
Mixed day schools & 1 & 17 \\
Day girls schools & 2 & 33 \\
Day Boys schools & 0 & 0 \\
\hline
\end{tabular}

Table 3. Percentage of $S$. aureus isolates carrying Mec A and PVL gene detected by PCR analysis.

\begin{tabular}{cc}
\hline Gene & $\%$ \\
\hline Mec A & $15 \%$ \\
PVL & $20 \%$ \\
PVL \& Mec A & $8 \%$ \\
\hline
\end{tabular}

in Lagos, Nigeria, isolates from telephone handles [11].

Tetracycline: No resistance was found in tetracycline all the isolates were sensitive to tetracycline. In almost a similar study in Lagos, Nigeria, isolates from telephone handles were only $33.3 \%$ who were sensitive to tetracycline [11].

Amoxyllin/Clavulanic acid: 2\% resistance was noted in the isolates, this was very low compared to $59.3 \%$ resistance in a study conducted in Nigeria on the handles of telephone booths [11].

Ampicillin: All the isolates were resistant to ampicillin. In a study done for residential indoors in Texas, $54.59 \%$ showed resistance to ampicillin [12].

Gentamycin: No resistance to gentamycin was noted in this study. In a study done in Lagos, Na igeria, isolates from telephone handles were also $100 \%$ sensitive to Gentamycin [11].

Cefoxitine resistance was seen in $15 \%$ the isolates, while all the isolates were sensitive to Clindamycin, Levofloxacin, and Vancomycin.

\subsection{Prevalence of Staphylococcus aureus in Different Types of Schools}

Staphylococcus aureus was common in Girls schools and mixed schools. No isolation was found among the boys school. This could be attributed to the fact that the boys use urinals in the toilets. The urinals do not have doors, so the risk of touching the door handles is unlikely. The girls will almost always touch the door handles as they have to touch the toilet handles when entering and coming out of the toilets. Staphylococcus aureus was found in four (Girls schools) out of 12 schools. Only two (Mixed schools) were positive for Staphylococcus aureus. Among the four girls schools two were boarding and the other two were day schools. Among the two mixed schools one was mixed none boarding and the other one mixed boarding school.

\subsection{Prevalence of $M e c A$ Gene}

Out of the 61 S. aureus isolated from the schools, $9(15 \%)$ had MecA gene. 5 (8\%) had both PVL and MecA genes.

\subsection{Prevalence of PVL Gene}

Out of the 61 of the S. aureus isolates $12(20 \%)$ contained the PVL gene. 5 (56\%) out 9 isolates containing MecA gene had PVL gene. A study done in France showed that most CA-MRSA contain the PVL gene [14].

\section{Conclusion}

The new data reveal that there is a presence MRSA in schools. Surveillance programs and researches should be done regularly to monitor the antibiotic patterns of 
MRSA. This will help curb the problem of developing resistance to antibiotics and more so resistance to methicillin. Hygine measures and education should be done in schools to prevent the spread of MRSA and other infectious diseases.

\section{Acknowledgements}

I would like to acknowledge Professor Samuel Kariuki for his unfailing support and enthusiasm during the entire research period, which enabled me to carry out and complete this project, Professor Anne Muigai whose rapid communication, critical appraisal and constructive comments were invaluable, the National Microbiology Reference laboratory for letting me to work in the lab and to all participating schools for their voluntary contribution to the study.

\section{REFERENCES}

[1] K. J. Ryan and C. G. Ray, "Sherris Medical Microbiology," 4th Edition, McGraw-Hill, New York, 2004.

[2] N. Cimolai, "MRSA and the Environment: Implications for Comprehensive Control Measures," European Journal of Clinical Microbiology \& Infectious Diseases: Official Publication of the European Society of Clinical Microbiology, Vol. 27, No. 7, 2008, pp. 481-493. http://dx.doi.org/10.1007/s10096-008-0471-0

[3] B. T. Cenci-Goga, M. Karama, P. V. Rossitto, R. A. Morgante and J. S. Cullor, "Enterotoxin Production by Staphylococcus aureus Isolated from Mastitic Cows," Journal of Food Protection, Vol. 66, No. 9, 2003, pp. 16931696.

[4] H. F. Chambers and F. R. DeLeo, "Waves of Resistance: Staphylococcus aureus in the Antibiotic Era," Nature Reviews Microbiology, Vol. 7, No. 9, 2009, pp. 629-641. http://dx.doi.org/10.1038/nrmicro2200

[5] A. Clauditz, A. Resch, K. P. Wieland, A. Peschel and F. Götz, "Staphyloxanthin Plays a Role in the Fitness of Staphylococcus aureus and Its Ability to Cope with Oxidative Stress," Infection and Immunity, Vol. 74, No. 8, 2006, pp. 4950-4953.

http://dx.doi.org/10.1128/IAI.00204-06

[6] M. Aires De Sousa and H. De Lencastre, "Bridges from Hospitals to the Laboratory: Genetic Portraits of Methicillin-Resistant Staphylococcus aureus Clones," FEMS Immunology and Medical Microbiology, Vol. 40, No. 2,
2004, pp. 101-111. http://dx.doi.org/10.1016/S0928-8244(03)00370-5

[7] T. Ito and K. Hiramatsu, "Acquisition of Methicillin Resistance and Progression of Multi Antibiotic Resistance in Methicillin-Resistant Staphylococcus aureus," YMJ: Yonsei Medical Journal, Vol. 39, 1998, pp. 526-533.

[8] K. Sieradzki and A. Tomasz, "Inhibition of Cell Wall Turnover and Autolysis by Vancomycin in a Highly Vancomycin-Resistant Mutant of Staphylococcus aureus," Journal of Bacteriology, Vol. 179, No. 8, 1997, pp. 2557 2566.

[9] G. A. J. Ayliffe, W. Brumfitt, M. W. Caewell, B. D. Cookson and G. Duckworth, "Working Party ReportRevised Guidelines for Control of Epidemic MethicillinResistant Staphylococcus aureus," Journal of Hospital Infection, Vol. 16, 1990, pp. 351-377. http://dx.doi.org/10.1016/0195-6701(90)90008-C

[10] I. M. Malonza, M. A. Omari, J. J. Bwayo, A. K. Mwatha, A. N. Mutere, E. M. Murage and J. O. Ndinya-Achola, "Community Acquired Bacterial Infections and Their Antimicrobial Susceptibility in Nairobi, Kenya," East African Medical Journal, Vol. 74, No. 3, 1997, pp. 166-170.

[11] S. I. Smith, B. Opere, H. T. Goodluck, O. T. Akindolire, A. Folaranmi, O. M. Odekeye and E. A. Omonigbehin "Antibiotic Susceptibility Pattern of Staphylococcus Species Isolated from Telephone Receivers," Singapore Medical Journal, Vol. 50, No. 2, 2009, pp. 208-211.

[12] A. M. Al-Mohana, A. H. Al-Charrakh, F. H. Nasir and M. K. Al-Kudhairy, "Community Acquired Methicillin-Resistant Staphylococcus aureus Carrying MecA and Panton Valentine leukocidin (PVL) Genes Isolated from the Holy Shrine in Najaf, Iraq," Journal of Bacteriology Research, Vol. 4, No. 2, 2012, pp. 15-23.

[13] A. Gandara, L. C. Mota, C. Flores, H. R. Perez, C. F. Green and S. G. S Gibb, "Isolation of Staphylococcus aureus and Antibiotic-Resistant Staphylococcus aureus from Residential Indoor Bioaerosols," Environmental Health Perspectives, Vol. 114, No. 12, 2006, pp. 1859 1864.

[14] P. Dufour, Y. Gillet, M. Bes, G. Lina, F. Vandenesch, D. Floret, J. Etienne and H. Richet, "Community-Acquired Methicillin-Resistant Staphylococcus aureus Infections in France: Emergence of a Single Clone that Produces Panton-Valentine Leukocidin," Clinical Infectious Diseases, Vol. 35, 2002, pp. 819-824.

http://dx.doi.org/10.1086/342576 